\title{
La humanidad aumentada La administración digital del mundo
}

DOI: https://doi.org/10.18861/ic.2018.13.1.2839

\section{POR RUBÉN BISELLI}

rubenbiselli@hotmail.com - Facultad de Ciencia Política y Relaciones Internaciones, Universidad Nacional de Rosario (UNR), Argentina.

SiÉric Sadin se encarga explícitamente de ubicar $L a$ humanidad aumentada (2017) en el contexto de una trilogía virtual integrada por dos ensayos anteriores (Surveillance globale, 2009, y La Société de l'anticipation, 2011), "donde se entrelazan observaciones y análisis relativos a la aptitud del 'ingenio electrónico’ para ampliar sin medida conocida nuestras capacidades cognitivas, para relevar nuestro juicio y responsabilidad, fisurando de este modo el zócalo fundamental de nuestras condiciones de existencia" (p. 35), el azar del momento de la publicación de la versión en español se articula con la irrupción explosiva en la prensa internacional de una temática persistente: los profundos "peligros" implícitos en la creciente e incesante irrupción de dispositivos basados en inteligencia artificial que atraviesan vastos dominios de lo social y se instalan en el corazón mismo de nuestras vidas privadas.

La común referencia en muchos artículos periodísticos (alentados por cierta polémica mediática instaurada entre stars de Silicon Valley y por los ecos del "affaire algorítmico" en torno a las presidenciales estadounidenses del año anterior) y en el ensayo de Sadin a famosos films de ciencia ficción del siglo XX que habrían imaginado con sutileza algunos de estos peligros (en primer lugar, 2001: Odisea del espacio) refuerza, sin duda, el efecto de serie. Sin embargo, lejos de la agitación más o menos sensacionalista de fantasmas apocalípticos que caracteriza a muchos de esos artículos, ellibro de Sadin intenta leer los hechos del presente en lo referido a la "administración algorítmica del mundo" como indicios de una mutación
ÉRIC SADIN AUMANIDAD AUMENTADA administración digital del mundo

Sadin, E. (2017). La humanidad aumentada. La administración digital del mundo. Buenos Aires: Caja Negra. $^{1}$ 
antropológica cuyos peligros deben delinearse con exactitud y claridad para intentar su conjura o para articular frente a ellos alguna modalidad de resistencia que, sin negar ni rechazar los aportes de la digitalización global del mundo, permita sostener una "divergencia a propósito de la inflexión operada por los flujos informacionales de lo cotidiano” (2017, p. 154) y seguir articulando una singularidad.

No obstante, esta postulación de un curso de acción política frente a la voluntad de dominio de la determinación algorítmica de la existencia, que irrumpe como una especie de deus ex machina hacia el final del libro, no es lo más interesante del ensayo de Sadin. Lo más relevante es el modo en que articula, desarrolla, ejemplifica la mutación antropológica acarreada por la digitalización global de la existencia y la universalización progresiva de dispositivos basados en inteligencia artificial capaces de autoaprendizaje y de "decisión autónoma".

Lo esencial de nuestro tiempo es para Sadin el estar viviendo, tal como se llama uno de los capítulos de su ensayo, "el pasaje de la revolución digital al advenimiento de una antrobología” (p. 37). Ya no se trata solamente de una extensión de la digitalización a todos los niveles de la realidad, tampoco es meramente de un proceso incesante de aumento exponencial de la capacidad de almacenamiento y procesamiento de datos por parte de las computadoras y de la velocidad de dicho procesamiento. Tampoco se trata de la posibilidad de interconexiones infinitas en tiempo real. Basado en lo anterior, se trata de la emergencia de dos cesuras antropológicas decisivas: por un lado, la paulatina aparición y universalización de sistemas expertos diseñados para el autoaprendizaje y capaces de "tomar decisiones" por fuera dela voluntad humana, en base a un conocimiento inasequible para cualquier sujeto individual o colectivo. Por otro, el advenimiento de una nueva subjetividad híbrida, completamente alejada ya de una humanidad potenciada por "prótesis" de cualquier tipo, "que mezcla de manera cada vez más estrecha, los cuerpos y la potencia deductiva de los procesadores según un orden de 'doble fuente cognitiva”' (p. 84) y la instauración "de una antrobología que combina íntimamente inteligencia humana y artificial, ya no en el marco de coyunturas individuales o colectivas excepcionales, sino para un número de secuencias cada vez más extensas de nuestra cotidianidad" (ibíd.).

La primera cuestión es, sin duda, la que más acerca el ensayo de Sadin a la discursividad distópica en torno a la inteligencia artificial que ha circulado profusamente desde 2017. Pero lo diferencial y lo sugestivo de su análisis se sostiene, en primer lugar, en el rastreo minucioso de los antecedentes de esta "voluntad de poder" de la informática que se fue articulando mucho antes de poseer los medios técnicos para ejecutarla; en segundo lugar, se sostiene en el diálogo que establece entre las "anticipaciones" teóricas (sobre todo en el campo de la filosofía francesa de la técnica, con especial énfasis en Ellul y un 
intrigante olvido de Virilio) y ficcionales sobre esta cuestión; y, por último, en los intentos de caracterizar con precisión las consecuencias políticas del dominio algorítmico de lo real.

Para Sadin, los verdaderos efectos políticos de la decisión algorítmica generalizada exceden el marco del ejercicio de la acción abiertamente política y confluyen en la instauración de un "alisado social":

\begin{abstract}
Poco a poco, emerge una gubernamentalidad algorítmica, y no solamente aquella que permite a la acción política determinarse en función de una infinidad de estadísticas y de inferencias proyectivas, sino incluso aquella que "a escondidas" gobierna numerosas situaciones colectivas e individuales. (...) Esta condición en vías de consolidación da cuenta de una "salida de lo político" fuera de su campo usual, descubriendo una gubernamentalidad robotizada, globalizada, individualizada y movida por intereses dispares que busca- regular el campo social con vistas a converger en la construcción de un entorno destinado a impedir en todo momento la mínima fricción, y que se aborda como un continuum común indefinidamente liso y altamente dinámico (p. 138).
\end{abstract}

Lo original de esta coyuntura técnico-cultural, indisociable del segundo aspecto de la cesura antropológica, es que este "alisado" político, en clara contraposición a lo que imaginaron las distopías de las décadas 20 y 30 del siglo XX, "no busca 'borrar las diferencias' ni 'uniformizar los regímenes' sino que, por el contrario, están adiestrados para exaltar al máximo cada circunstancia singular. La inteligencia computacional domina un arte del kairós, para efectuar una adecuación universal que opera instante a instante" (p. 139).

La instauración de una nueva subjetividad híbrida -que Sadin denomina humanidad aumentada y a la cual ya nos referimos- aparece como el complemento indisociable de la gubernamentalidad algorítmica del mundo. Y, podríamos decir, que es lo que garantiza su eficacia política y su instauración casi sin resistencias en la trama social global. El smartphone devino, a la vez, su dispositivo-enseñay, por medio de sus aplicaciones, el espacio privilegiado desu despliegue. Sejuega allíla apuesta central de un dominio algorítmico dela praxis humana quelogra hacer indisociables una revocación inédita del poder de decisión autónomo -emblema de la libertad humana- y una experiencia no menos inédita de profundización de los poderes perceptivos, cognitivos y sensoriales de la especie humana. Es decir, un régimen dual de experiencia permitido por "la capacidad de los robots" y el saber algorítmico generalizado. "Son juegos de entrelazamientos que oscilan de facto entre la adquisición de una subjetividad altamente informada y la modificación de las decisiones por obra de algoritmos con poderes eminentemente seductores" (p. 84 y 85 )

Es a partir de esto, y más allá de los efectos positivos implicados, que Sadin ni siquiera se detiene en cuestionar que lo que debería remarcarse para él sobre los cada vez más habituales dispositivos basados en inteligencia artificial, por su 
invisibilidad funcional, es su poder de instaurar "una 'administración soft' y de apariencia casi lúdica de las existencias, confirmando 'un pliegue algorítmico' de lo cotidiano y descubriendo un horizonte concebido, de ahora en adelante, como un parque temático indefinidamente modulado a la singularidad de cada ser" (p. 85).

Yahemos señaladola propuesta de "acción política” sugerida por Sadin para enfrentar esta modalidad de gobernabilidad algorítmica y la subjetivización derivada de ella. También expusimos las razones por las cuales estos aspectos no nos parecían demasiado relevantes. Pero sílo es un tema al que Sadin vuelve, de manera oblicua, una y otra vez: como ha sucedido a lo largo de la historia de la mediatización moderna. No puede entenderse el cambio antropológico radical al que nos hemos estado refiriendo, y lo que podríamos denominar su aceptación gozosa, sin la extraña imbricación de tecnologías sofisticadas e imaginarios ligados a estructuras psíquicas de primitivismo radical.

De última, la "humanidad aumentada" asistida algorítmicamente -en su límite, y gracias a los poderes predictivos y adaptativos mágicos de los algoritmos- es una humanidad finalmente liberada, imaginariamente, delos poderes disruptivos del azar, de lo imprevisto, de lo que, de golpe, nos lanza desamparados a la intemperie de lo real.

\section{IDENTIFICACIÓN DEL AUTOR}

Rubén Biselli es docente e investigador de la Facultad de Ciencia Política y RR.II. de la Universidad Nacional de Rosario (UNR), Argentina. Es profesor adjunto de las cátedras de "Lenguajes I" y "Lenguajes III" y profesor titular de "Narrativas Mediáticas" en la Licenciatura en Comunicación Social y se desempeña como investigador en el Centro de Investigaciones en Mediatizaciones (CIM). Es co-autor de los libros Introducción a los lenguajes: La Fotografía (2000) e Interfaces y Pantallas (2011) y autor de artículos referidos a teoría literaria, análisis del discurso, semiótica de la imagen y teoría de los medios. 